\title{
Talking About, Knowing About HIVIAIDS in Canada: A Rural-Urban Comparison
}

\author{
Tiffany C. Veinot, $\mathrm{PhD}^{1}$ \& Roma Harris, $\mathrm{PhD}^{2}$ \\ 1 School of Information and School of Public Health, University of Michigan, Ann Arbor, Michigan \\ 2 Faculty of Information and Media Studies, The University of Western Ontario, London, Ontario, Canada
}

Financial support for this project was generously provided by the Canadian Institutes for Health Research under the Federal Initiative to address HIVIAIDS in Canada. For further information, contact: Tiffany C. Veinot, PhD, School of Information and School of Public Health, University of Michigan, 4429 North Quad, 105 S. State Street, Ann Arbor, Ml 48109-1285; e-mail tveinot@umich.edu.

doi: 10.1111/j.1748-0361.2010.00353.x

\begin{abstract}
Purpose: To explore information exchange about HIV/AIDS among people living in rural and urban communities and to assess the value of social capital theory, as well as demographic factors, in predicting community members' knowledge of HIV/AIDS and their likelihood of having talked about the disease.

Method: A random-digit dial telephone survey was conducted in 3 rural regions and matched urban communities in Canada during 2006 and 2007. A total of 1,919 respondents (response rate: $22.2 \%$ ) answered questions about their knowledge of and attitudes toward HIV/AIDS, their social networks, whether they were personally acquainted with a person with HIV/AIDS (PHA), and whether they had ever talked to anyone about HIV/AIDS.

Findings: Rurality was a significant predictor of HIV/AIDS knowledge and discussion. Even after controlling for factors such as age and level of education, respondents living in rural regions were less knowledgeable about HIV/AIDS and were less likely to have spoken with others about the disease. Social capital theory was not as strongly predictive as expected, although people with more bridging ties in their social networks were more likely to have discussed the disease, as were those who knew a PHA personally.

Conclusion: Rural-dwelling Canadians are less likely than their urban counterparts to be knowledgeable about HIV/AIDS or to talk about it, confirming reports by PHAs that rural communities tend to be silent about the disease. The findings support policy recommendations for HIV education programs in rural areas that encourage discussion about the disease and personal contact with PHAs.
\end{abstract}

Key words HIV/AIDS knowledge, information behavior, rural-urban differences, social capital.
Disparities in rural-urban population health and access to care are significant problems in many countries, including Canada. Canadians who live in rural areas have shorter life expectancies and higher rates of chronic illness and disability than their urban counterparts, ${ }^{1-3}$ and many face challenges in access to health care as a result of shortages in local health care providers and long distances to travel, particularly for specialized care., ${ }^{4,5}$ Access issues are particularly significant for people living with HIV/AIDS (PHAs) who reside in rural areas. Because HIV/AIDS is treated primarily by specialists, disease-related treatment is usually concentrated in tertiary urban-based centers and, where rural support services do exist, PHAs may be reluctant to use them due to concerns over confidentiality. ${ }^{6,7}$ Similar problems for rural-dwelling PHAs have been reported in the United States and Australia. ${ }^{8,9}$

\section{Knowing About HIV: Routes of Information Exchange}

Access to a supportive community is important to anyone coping with a chronic health condition. However, the stigma associated with HIV/AIDS can pose a 
significant barrier to such support. Research suggests that the more knowledgeable people are about HIV/AIDS, the less likely they are to hold discriminatory beliefs and to distance themselves from PHAs. ${ }^{10}$ However, knowledge levels about the disease vary from community to community. In the United States, rural dwellers have been found to be less knowledgeable about HIV/AIDS than people who live in urban areas, ${ }^{11-13}$ and some populations within rural areas are less knowledgeable than others about sexually transmitted infections. ${ }^{14}$ Lack of knowledge about HIV/AIDS can lead not only to intolerance and stigmatization of PHAs, but it also carries its own health risks. Indeed, it has been argued that "inadequate knowledge of HIV and indifference to prevention messages" can contribute to "inaccurate perceptions of personal risk factors." 13

Although common sources of health information increasingly include the Internet, ${ }^{15}$ along with other media such as television and newspapers, "incidental information acquisition" through everyday conversation, particularly with family members and friends, is also a significant means by which people exchange health information and keep up to date. ${ }^{16}$ Indeed, in a study of rural women's health information seeking, it was reported that a considerable number of the participants relied upon "support for their health needs from others in their social networks" more so than from health care providers, including physicians. ${ }^{17}$ However, this type of support may not be available if people are reluctant to discuss stigmatized health conditions, such as HIV/AIDS. In Canada, rural PHAs and their family members and friends report that their communities are marked by a pervasive silence about HIV/AIDS and that when information about the disease is exchanged, it is often incorrect. ${ }^{18}$ As a result, an important method of maintaining community health knowledge may be lost and opportunities to offer and receive support forgone. ${ }^{19}$

These findings raise important questions about the factors that influence health knowledge in local communities. Social capital theorists regard the acquisition of information, including health knowledge, to be a key benefit of social networks. ${ }^{20,21}$ Different types of connections or "ties" between network members are expected to influence access to specific types of information. For instance, "bonding" social capital refers to "strong" ties between socially similar people where there is considerable overlap in the relationships between network members. Where such dense social networks exist, information tends to spread quickly, but it is often redundant. ${ }^{22-24}$ In contrast, "bridging" social capital involves connections or "weak" ties between socially or spatially distant people. These ties tend to facilitate access to novel information..$^{23,25}$ Because rural residents have been reported to have higher levels of bonding social capital and lower levels of bridging social capital in their personal networks than do urban residents, ${ }^{26}$ the differences in their personal networks may influence the level of discussion of information about HIV/AIDS and resulting knowledge of the disease in rural and urban communities. Also relevant to the acquisition of health knowledge through social networks is whether network members know people with particular medical conditions. ${ }^{27}$ Given that the reported prevalence of HIV/AIDS in many rural Canadian communities is quite low, rural dwellers may be less likely than people living in urban areas to know a PHA personally and may, therefore, be less knowledgeable about the disease.

In the population study reported here, we examine several factors that might influence the level of knowledge and discussion of HIV/AIDS among Canadians living in rural and urban areas, including attitudes toward the disease, knowing a PHA personally, the roles of bonding and bridging social capital, and demographic factors including age and education.

\section{Method}

Random-digit dial telephone population surveys were conducted between October 2006 and August 2007 in rural and neighboring urban regions in 3 Canadian provinces. We used the Organisation for Economic Cooperation and Development (OECD) definition of "rurality," which includes regions with a population density of less than 100 persons per square kilometer. ${ }^{28}$ The population density approach to defining "rurality" was selected to highlight the specific challenges of providing HIV/AIDS-related services in regions with both low population density and a relatively low HIV/AIDS prevalence. The boundaries of these rural regions were further chosen to align with the territorial organization of HIV/AIDS, health and/or social services serving the areas. The rural regions included: (1) two adjacent agricultural counties in southwestern Ontario with a combined population density of 23.81 people per square kilometer (an area in which an estimated 41 people had been diagnosed with HIV/AIDS); ${ }^{29}$ (2) three adjacent regional districts in a mountainous central region of British Columbia (BC) with a combined population density of 4.30 people per square kilometer (with an estimated 72 PHAs) ${ }^{30}$ and (3) nine census divisions on the island of Newfoundland with a combined population density of 2.96 people per square kilometer (with an estimated 45 PHAs). ${ }^{30}$ For comparative purposes, surveys were also conducted in the 3 urban areas closest to the rural study areas. Each of these urban areas had a population density of greater than 225 people per square kilometer, and each was also the location 
Figure 1 Study Regions: Kootenay Region and Kelowna (British Columbia); Huron and Perth Counties and London (Ontario) and Rural Newfoundland Island and St. John's (Newfoundland)

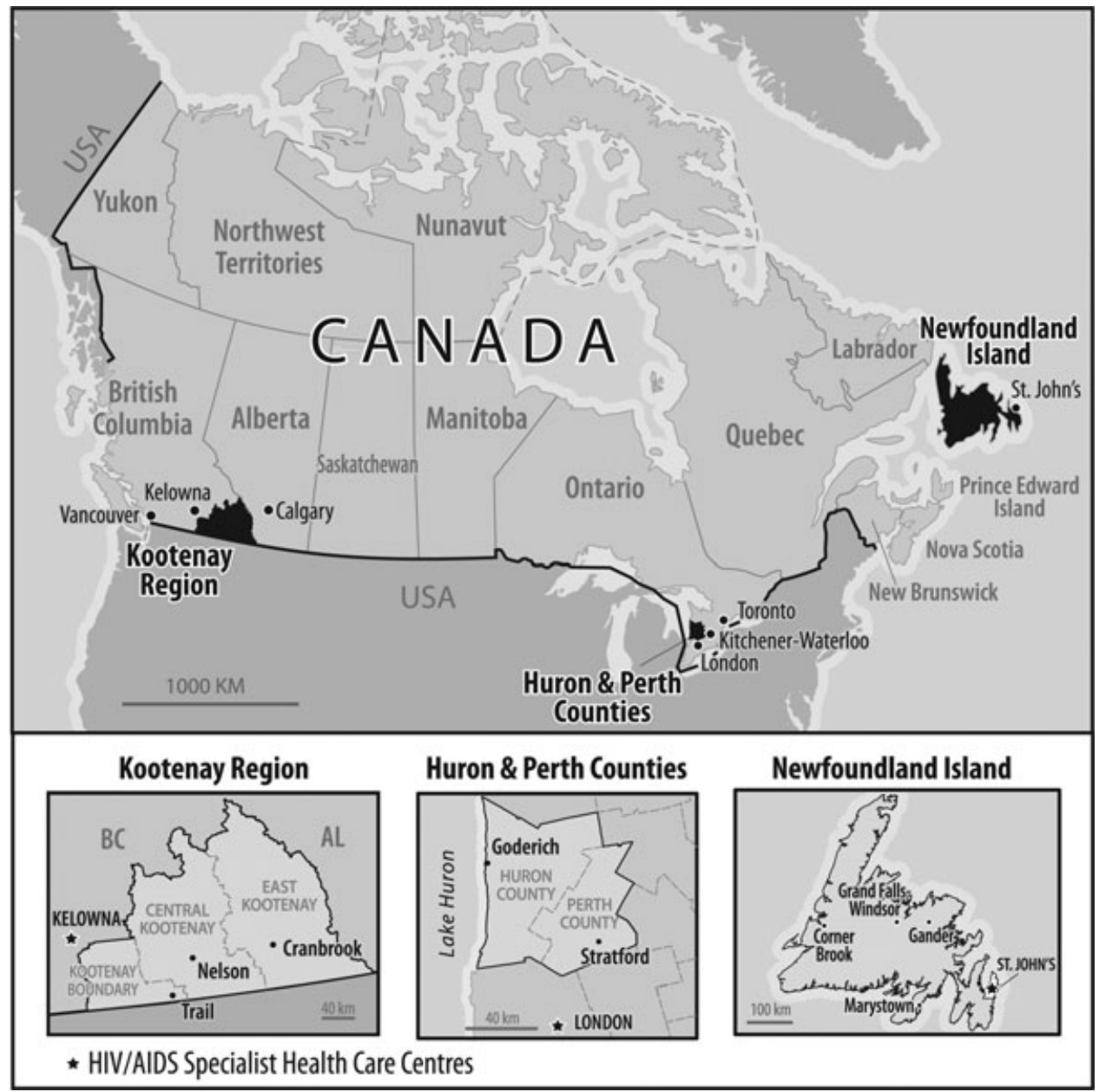

of regional HIV/AIDS specialist health care centers (see Figure 1 for a map of the study regions).

Within each region, a sample frame was created from a random selection of published, noncellular telephone numbers stratified by census division. ${ }^{\text {a }}$ A total of 49,022 telephone calls were made to 12,887 numbers. A maximum of 10 calls were made to each number at different times of day, with an average of 4 calls per telephone number. Of the 8,898 eligible respondents (persons aged 18 or over) contained in the sampling frame, 6,923 refused to participate and $1,975(22.2 \%)$ agreed to complete the survey. In total, 1,177 people from the 3 rural

a This survey was conducted in late 2006 and early 2007, when cellular phone penetration was less extensive than it is today. The age distribution of our sample suggests that our sample did not systematically exclude younger people due to their greater reliance upon cellular phones. regions and 742 people from the matched urban areas took part in the study.

During the telephone survey, respondents were asked to provide demographic information (age, sex, and level of education) and to respond to a series of questions about their knowledge of and attitudes toward HIV/AIDS, their social networks, whether they knew a PHA personally, and whether they had ever talked to anyone about HIV/AIDS.

\section{Variables}

HIV/AIDS knowledge was assessed through 6 true/false questions drawn from an existing instrument. ${ }^{31,32}$ The items were selected based on their high correlation with overall HIV/AIDS knowledge scores in previous studies. Scores from the 6 items were combined to create an HIV/AIDS knowledge index (Cronbach's alpha $=0.64)$. 
Because the distribution of index scores was highly skewed, a binary variable was created for the purpose of analysis (where scores below the mean $=0$ and those above $=1$ ). Attitudes toward the disease were assessed through 4 questions drawn from an existing measure, ${ }^{33}$ each of which is highly correlated with total scores on the original attitude scale. Likert-scale responses to the 4 items were combined and transformed using z-scores to create a mean attitude score for each participant.

Respondents' estimates of the number of people they feel "very close to" or "somewhat close to" were used to represent stronger and weaker social network ties, respectively. ${ }^{34}$ As well, the proportion of a respondent's network members who live "more than 1 hour's travel away from where you live" was used as a measure of network proximity, ${ }^{34}$ and the proportion of a respondent's network members who "know one another" was used a measure of network density. For the purpose of analysis, bonding and bridging social capital were operationalized as composite variables. Bonding social capital was calculated by combining the proportion of strong ties in a respondent's social network and network density. The proportion of strong ties was calculated by dividing the number of strong ties for each respondent by the total number of their personal network ties. The resulting distribution was divided by quartiles into 4 categories ranging from "low" to "high." The distribution of network density scores was also divided into 4 categories. The 2 variables were combined, using the median values for each as a cutpoint to create the binary variable "bonding social capital" (where 1 = high bonding social capital and $0=$ low bonding social capital). Similarly, to calculate bridging social capital, we used measures of geographic dispersion ${ }^{35}$ and the number of weaker ties in the respondents' networks. The distributions of the variables "network proximity" and "number of weaker ties" were transformed into quartiles ranging from low to high. The 2 variables were combined, using the median values for each as a cutpoint to create the binary variable "bridging social capital" (where $1=$ high bridging capital and $0=$ low bridging capital).

\section{Data Analysis}

Bivariate logistic regression was used to examine unadjusted associations between sex, age, level of education, living in a rural or urban community, knowing a PHA, attitudes toward HIV/AIDS, and the likelihood of discussing or having high knowledge of HIV/AIDS. After screening variables for multicollinearity, multiple logistic regression was used to estimate adjusted ORs and 95\% CI for adjusted associations among the variables. These analyses allowed us to assess whether rural-urban differences per- sisted after adjustment for demographic differences between rural and urban residents, and to identify what other factors were associated with discussion and knowledge. Because there was little variability in the results between geographic regions in which we collected data, we report here the results of analyses based on the combined data from the 3 study regions. Analyses were conducted using SPSS (SPSS Inc., Chicago, Illinois) statistical software. This study was approved by The University of Western Ontario's Office of Research Ethics.

\section{Results}

\section{Sample Characteristics}

As shown in Table 1, more women than men participated in the survey and proportionally more people aged 50 years and older took part. Nevertheless, survey respondents in 2 rural regions were younger and had higher levels of education than the regions' respective populations, and in the third rural region, the age and

Table 1 Sample Characteristics, by Urban/Rural Residence $(N=1919)^{a}$

\begin{tabular}{|c|c|c|c|}
\hline Characteristics & $\begin{array}{c}\text { Rural\% } \\
(\mathrm{N}=1,177)\end{array}$ & $\begin{array}{c}\text { Urban\% } \\
(\mathrm{N}=742)\end{array}$ & $P$ Value $^{\mathrm{b}}$ \\
\hline \multicolumn{4}{|l|}{ Demographics } \\
\hline \multicolumn{4}{|l|}{ Age } \\
\hline 18 to 29 & 10.9 & 19.1 & \multirow[t]{5}{*}{$<.001$} \\
\hline 30 to 39 & 19.9 & 15.9 & \\
\hline 40 to 49 & 22.0 & 21.8 & \\
\hline 50 to 64 & 32.7 & 30.3 & \\
\hline 65 or older & 14.4 & 12.8 & \\
\hline \multicolumn{4}{|l|}{ Education } \\
\hline Less than high school & 14.7 & 6.7 & \multirow[t]{3}{*}{$<.001$} \\
\hline High school & 34.9 & 35.7 & \\
\hline Education beyond high school & 50.3 & 57.7 & \\
\hline \multicolumn{4}{|l|}{ Gender } \\
\hline Male & 68.2 & 69.3 & \multirow[t]{2}{*}{.62} \\
\hline Female & 31.8 & 30.7 & \\
\hline \multicolumn{4}{|l|}{ Network characteristics } \\
\hline \multicolumn{4}{|l|}{ Bonding social capital } \\
\hline Below mean & 34.6 & 35.9 & \multirow[t]{2}{*}{.58} \\
\hline Above mean & 65.4 & 64.1 & \\
\hline \multicolumn{4}{|l|}{ Bridging social capital } \\
\hline Below mean & 63.5 & 67.0 & \multirow[t]{2}{*}{.11} \\
\hline Above mean & 36.5 & 33.0 & \\
\hline PHA(s) known personally & 17.0 & 21.1 & .02 \\
\hline Has ever discussed HIVIAIDS & 51.2 & 60.5 & $<.001$ \\
\hline Positive attitudes ${ }^{c}$ & 87.6 & 89.3 & .38 \\
\hline Knowledge scores ${ }^{d}$ & 67.7 & 73.3 & $<.001$ \\
\hline
\end{tabular}

${ }^{a}$ Excludes 56 participants who terminated prior to completion of the entire survey.

${ }^{\mathrm{b}} P$ values from chi square tests of independence.

'Mean\% of disagreement with 4 negative statements about HIVIAIDS.

dMean\% of correct responses to 6 HIVIAIDS knowledge questions. 
Table 2 Logistic Regression Model of Having Ever Discussed HIVIAIDS

\begin{tabular}{|c|c|c|c|c|}
\hline Predictors of Discussion & $\begin{array}{c}\text { Unadjusted OR } \\
(95 \% \mathrm{Cl})\end{array}$ & $P$ Value & $\begin{array}{l}\text { Adjusted OR } \\
\qquad(95 \% \mathrm{Cl})\end{array}$ & $P$ Value \\
\hline \multicolumn{5}{|l|}{ Residence } \\
\hline Rural & $0.69(0.57-0.83)$ & \multirow[t]{2}{*}{$<.001$} & $0.78(0.63-0.97)$ & \multirow[t]{2}{*}{.02} \\
\hline Urban & 1.00 (ref) & & 1.00 (ref) & \\
\hline \multicolumn{5}{|l|}{ Demographics } \\
\hline \multicolumn{5}{|l|}{ Age } \\
\hline $18-39$ & 1.00 (ref) & & 1.00 (ref) & \\
\hline $40-49$ & $0.88(0.69-1.13)$ & .32 & $0.90(0.68-1.19)$ & .45 \\
\hline $50-64$ & $0.91(0.73-1.14)$ & .41 & $1.06(0.82-1.37)$ & .66 \\
\hline$\geq 65$ & $0.38(0.28-0.51)$ & $<.001$ & $0.61(0.43-0.85)$ & .004 \\
\hline \multicolumn{5}{|l|}{ Education } \\
\hline Less than high school & 1.00 (ref) & & 1.00 (ref) & \\
\hline High school graduate & $2.43(1.74-3.38)$ & $<.001$ & $1.79(1.24-2.58)$ & .002 \\
\hline Education beyond high school & $4.65(3.38-6.41)$ & $<.001$ & $3.07(2.15-4.41)$ & $<.001$ \\
\hline \multicolumn{5}{|l|}{ Gender } \\
\hline Female & $1.47(1.21-1.78)$ & $<.001$ & $1.45(1.16-1.81)$ & \multirow[t]{2}{*}{.001} \\
\hline Male & 1.00 (ref) & & 1.00 (ref) & \\
\hline \multicolumn{5}{|l|}{ Network characteristics } \\
\hline \multicolumn{5}{|l|}{ Bonding social capital } \\
\hline Above mean & $0.79(0.65-0.96)$ & .02 & $0.95(0.76-1.18)$ & \multirow[t]{2}{*}{.63} \\
\hline Below mean & 1.00 (ref) & & 1.00 (ref) & \\
\hline \multicolumn{5}{|l|}{ Bridging social capital } \\
\hline Above mean & $1.62(1.33-1.97)$ & $<.001$ & $1.44(1.16-1.80)$ & \multirow[t]{2}{*}{.001} \\
\hline Below mean & 1.00 (ref) & & 1.00 (ref) & \\
\hline \multicolumn{5}{|l|}{ PHA(s) Known } \\
\hline Yes & $3.96(3.02-5.21)$ & $<.001$ & $3.28(2.43-4.42)$ & \multirow[t]{2}{*}{$<.001$} \\
\hline No & 1.00 (ref) & & 1.00 (ref) & \\
\hline Attitudes toward HIVIAIDS & $1.85(1.60-2.15)$ & $<.001$ & $1.50(1.27-1.78)$ & $<.001$ \\
\hline
\end{tabular}

a Model Summary: (-2) Log likelihood: 2137.08; Nagelkerke $R^{2}$ : 0.18 .

education distribution of the sample mirrored that of the population. ${ }^{30}$ There were no significant differences between the rural and urban respondents in their levels of bonding or bridging social capital or in the proportion of respondents who endorsed positive attitudes toward HIV/AIDS.

\section{Talking About HIV}

Rural respondents were significantly less likely than urban respondents to be personally acquainted with a PHA and just over half the rural respondents had ever talked about HIV/AIDS to anyone, significantly fewer than the $60.5 \%$ of urban respondents who had done so. As shown in Table 2, older respondents were less likely to have ever talked with another person about HIV/AIDS than younger participants, men were less likely to have discussed the disease than women, and those with less than a high school education were less likely to have talked about the disease with another person than respondents with more education.

The unadjusted odds of having discussed HIV/AIDS with anyone were $31 \%$ lower for rural residents than ur- ban residents, and the adjusted model shows that even after accounting for demographic and other variables, rural dwellers were still $22 \%$ less likely to have discussed HIV/AIDS (see Table 2).

In the unadjusted model, the characteristics of respondents' social networks were significant predictors of whether they had talked about HIV. As predicted by social capital theory, high bonding social capital led to a $21 \%$ reduction in the odds of discussion, while people with high bridging social capital were 1.62 times more likely to have discussed the disease. In the adjusted model, bonding social capital was no longer a significant predictor; however, people with high bridging social capital were still 1.45 times more likely to have discussed the disease. Knowing a PHA personally significantly increased the odds of having discussed the disease (by 3.96 times in the unadjusted model and 3.28 times in the adjusted model). Respondents with more positive attitudes toward the disease were significantly more likely to have discussed the disease (more positive attitudes increased the odds of having discussed HIV/AIDS with another person by 1.50 times).

Overall, the adjusted model explained a moderate amount of the variance in whether respondents had ever 
Table 3 Logistic Regression Model of High HIVIAIDS Knowledge

\begin{tabular}{|c|c|c|c|c|}
\hline Predictors of High HIVIAIDS Knowledge & $\begin{array}{c}\text { Unadjusted OR } \\
(95 \% \mathrm{Cl})\end{array}$ & $P$ Value & $\begin{array}{l}\text { Adjusted OR } \\
\qquad(95 \% \mathrm{Cl})\end{array}$ & $P$ Value \\
\hline \multicolumn{5}{|l|}{ Residence } \\
\hline Rural & $0.69(0.57-0.83)$ & $<.001$ & $0.80(0.64-0.98)$ & .04 \\
\hline Urban & 1.00 (ref) & & 1.00 (ref) & \\
\hline \multicolumn{5}{|l|}{ Demographics } \\
\hline \multicolumn{5}{|l|}{ Age } \\
\hline $18-39$ & 1.00 (ref) & & 1.00 (ref) & \\
\hline $40-49$ & $0.95(0.74-1.23)$ & .72 & $1.01(0.76-1.34)$ & .93 \\
\hline $50-64$ & $0.62(0.50-0.78)$ & $<.001$ & $0.64(0.49-0.82)$ & $<.001$ \\
\hline$\geq 65$ & $0.26(0.19-0.36)$ & $<.001$ & $0.37(0.26-0.53)$ & $<.001$ \\
\hline \multicolumn{5}{|l|}{ Education } \\
\hline Less than high school & 1.00 (ref) & & 1.00 (ref) & \\
\hline High school graduate & $2.65(1.86-3.79)$ & $<.001$ & $1.75(1.18-2.58)$ & .005 \\
\hline \multicolumn{5}{|l|}{ Gender } \\
\hline Female & $1.15(0.95-1.41)$ & .15 & $1.05(0.84-1.31)$ & .70 \\
\hline Male & 1.00 (ref) & & 1.00 (ref) & \\
\hline \multicolumn{5}{|l|}{ Network characteristics } \\
\hline \multicolumn{5}{|l|}{ Bonding social capital } \\
\hline Above mean & $0.77(0.63-0.94)$ & .01 & $0.87(0.70-1.08)$ & .21 \\
\hline Below mean & 1.00 (ref) & & 1.00 (ref) & \\
\hline \multicolumn{5}{|l|}{ Bridging social capital } \\
\hline Above mean & $1.19(0.98-1.45)$ & .08 & $0.93(0.74-1.16)$ & .51 \\
\hline Below mean & 1.00 (ref) & & 1.00 (ref) & \\
\hline \multicolumn{5}{|l|}{ PHA(s) known } \\
\hline Yes & $1.36(1.03-1.80)$ & $<.001$ & $1.37(1.04-1.80)$ & .03 \\
\hline No & 1.00 (ref) & & 1.00 (ref) & \\
\hline \multicolumn{5}{|l|}{ Has discussed HIVIAIDS } \\
\hline Attitudes toward HIVIAIDS & $1.84(1.58-2.16)$ & $<.001$ & $1.51(1.26-1.80)$ & $<.001$ \\
\hline
\end{tabular}

a Model Summary: (-2) Log likelihood: 2113.32; Nagelkerke $R^{2}$ : 0.17.

talked about HIV/AIDS with someone else (Nagelkerke $R^{2}=0.18$ ).

\section{Knowledge of HIVIAIDS}

There were significant rural-urban differences in the proportion of correct responses to the HIV/AIDS knowledge questions. Notably, significantly more of the rural respondents believed that HIV/AIDS might be transmitted through casual contact with a PHA than did urban dwellers $(24.9 \%$ vs $19.0 \% ; P=.02)$. As shown in Table 3 , in the unadjusted model, rural dwellers were $31 \%$ less likely to have scored "high" in knowledge of HIV/AIDS and they were $20 \%$ less likely to have high knowledge scores in the adjusted model.

Age and education were also significant predictors of high HIV/AIDS knowledge in both the unadjusted and adjusted models. In the adjusted model, people aged 50 years and older were $36 \%$ less likely, and people
65 years or older were $63 \%$ less likely to have "high" knowledge of HIV/AIDS. Additionally, in the adjusted model, high school graduates were 1.75 times and people with education beyond high school were 2.36 times more likely to have high knowledge of the disease.

Although bonding social capital was a significant predictor of high knowledge in the unadjusted model (respondents with high bonding social capital were $23 \%$ less likely to have high knowledge), it was not significant in the adjusted model. Bridging social capital was not a significant predictor in either model. However, knowing a PHA personally was a significant predictor of knowledge, with respondents who knew a PHA being 1.36 times more likely in the unadjusted and 1.37 times more likely in the adjusted model to have high knowledge of the disease than those who did not know a PHA personally.

Respondents who had discussed the disease with others were more likely to have higher levels of knowledge of HIV/AIDS than those who had never done so (2.00 times 
higher in the unadjusted model and 2.08 times higher in the adjusted model), and those with more positive attitudes toward HIV/AIDS were also 1.51 times more likely to have greater knowledge of the disease (in the adjusted model).

Overall, the adjusted model explained a moderate amount of variance in knowledge (Nagelkerke $R^{2}=$ $0.17)$.

\section{Discussion}

This is one of the few studies of which we are aware that examines rural-urban differences in discussion of and knowledge about HIV/AIDS in the lay population. A key contribution of this research is the result that, even after adjusting for demographic and other variables, "rurality" is a significant predictor of knowledge of HIV/AIDS as well as the likelihood that people have talked about the disease with others. Our finding that rural-dwelling Canadians are less knowledgeable about HIV/AIDS than their urban counterparts is consistent with results reported in US studies. ${ }^{11-13}$ Moreover, identifying that rural dwellers are less likely than those who live in neighboring urban areas to have ever discussed HIV/AIDS with another person gives credence to reports from PHAs and their family members that rural communities in Canada are largely silent about HIV/AIDS. ${ }^{18}$

The results of our survey also revealed other factors associated with lack of knowledge about HIV/AIDS including older age, lower levels of education, less positive attitudes toward the disease, and not being personally acquainted with a PHA. These factors are also associated with not having talked about the disease. Although it may be the result of a social desirability effect, it is noteworthy that the majority of respondents in this study did not openly endorse negative attitudes about HIV/AIDS (a finding consistent with results reported in the United States). ${ }^{36}$ We also found that, as predicted by social capital theorists, lack of talk about HIV/AIDS is linked to a lack of social "bridging" capital, that is, links to people in one's social network other than to whom one is "very close," live further away, and that facilitate access to novel information. However, bonding social capital was not a significant predictor of discussion once other factors were taken into account. Moreover, knowledge of HIV/AIDS was not significantly associated as we had expected with either bonding or bridging capital after adjustment for other variables. Accordingly, our results suggest that the relationships between social capital, information exchange and knowledge are more complex than has been previously suggested.

The constellation of results that indicate that knowledge about HIV/AIDS is related to knowing someone personally who has HIV/AIDS, talking about the disease and having ties with people who are not connected only to one's most intimate social group, suggests that ideas about "incidental information acquisition"16 and "information exposure" via social networks ${ }^{37}$ have particular merit in furthering our understanding of health information exchange. This may be especially relevant to tightly knit rural communities where people may experience the conundrum of balancing the benefits of support that often comes with overlapping, long-term relationships, alongside the pressure to uphold community norms ${ }^{38}$ and the challenge of maintaining personal privacy. Moreover, this process is complicated by the geographic distribution of expertise, such that specialized health knowledge may be missing in a given community. ${ }^{30}$ As we have suggested elsewhere, understanding the role of lay health "info(r)mediaries" in such settings is important to discovering how people learn about and manage their health concerns. $^{39}$

Although not measured in this study, previous research on "community boundedness" 40 indicates that rural dwellers' sense of community affiliation may shape their collective sense of the relative importance of various issues, leading them to give less attention to people who face concerns regarded by the community to be unimportant. ${ }^{38}$ Indeed, PHAs and their family members suggest that HIV/AIDS is not perceived to be important or even relevant at the community level in rural areas where residents may deny its existence, locally, and perceive it to be a "big city problem." 44 Our findings suggest a need for further research about the dynamics of community-level information flow and knowledge related to HIV/AIDS. Comparative research about HIV/AIDS information exchange in communities with higher HIV/AIDS prevalence, for instance with gay men in an urban setting, may be useful in revealing the relative importance of the community boundedness concept to community-level discussion of and knowledge about the disease.

\section{Implications}

An encouraging aspect of this study concerns the modifiable, significant predictors of HIV discussion and knowledge. With respect to HIV/AIDS knowledge, discussing the disease and knowing a PHA personally have been shown to be significant predictive variables. Indeed, the importance of knowing a PHA personally is consistent with research that has repeatedly shown personal relevance to be a predictor of knowledge about health topics $^{39}$ as well as greater knowledge of, and information seeking about, HIV/AIDS. ${ }^{44}$ Given the connection between lack of HIV knowledge and negative attitudes toward PHAs, ${ }^{43,10}$ our results provide support for policy 
recommendations to include personal contact with PHAs in community-based HIV/AIDS education and stigma reduction programs. ${ }^{44}$ In addition, the positive relationship between knowledge of HIV/AIDS and talking about it with others suggests that promoting discussion may be an important way to increase local knowledge and reduce stigmatization of the disease.

\section{Limitations}

Several important limitations should be kept in mind when interpreting results of this study. First, its crosssectional nature means that it is not possible to identify causal relationships between the variables. Second, the sample response rate was low in that only $22.2 \%$ of potential respondents agreed to participate in the study. Third, the samples drawn from each region included in the study differed from the general populations of these areas. Specifically, a higher proportion of women participated in the study than are found in the general population and survey participants in 2 rural regions had higher education levels, and were younger than, the general population. It is worth noting, however, that the demographic composition of the sample may have led to underestimation of trends we found in the data. For instance, the greater number of women and the proportion of better educated participants found in the sample may have resulted in an overestimation of the proportion of people in the population who had ever talked about HIV/AIDS.

\section{Conclusion}

This study is among the few that have compared knowledge of and talk about HIV/AIDS between rural and urban populations. Low levels of discussion about and knowledge of the disease suggest that, relative to neighboring urban centers, rural Canadian communities are not yet fully understanding toward the PHAs who live in their midst. Given that rurality is a significant predictor of HIV/AIDS knowledge and discussion about the disease, further research about the dynamics of health information exchange and knowledge formation in rural communities seems warranted. Our results suggest that education strategies aimed at facilitating discussion of the disease between community members and a greater personal connection with PHAs may be beneficial. As Shapiro observed about HIV education, "If knowledge breeds comfort; and, if comfort can promote compassion; then, perhaps, greater compassion from the noninfected community can contribute to a higher quality of life for those persons currently afflicted."10

\section{References}

1. Sutherns R, McPhedran M, Haworth-Brockman M. Rural, Remote and Northern Women's Health: Policy and Research Directions. Final Summary Report. Winnipeg: Centres of Excellence for Women's Health; 2004.

2. Mitura V, Bollman RD. The health of rural Canadians: a rural-urban comparison of health indicators. Rural Small Town Canada Anal Bull. 2005; 4(6):1-23. Available at: http://

www.statcan.gc.ca/pub/21-006-x/21-006-x2002006eng.pdf. Accessed October 31, 2010.

3. DesMeules M, Pong R. How Healthy Are Rural Canadians? An Assessment of Their Health Status and Health Determinants. Ottawa: Canadian Institute for Health Information; 2006.

4. Ng E, Wilkins R, Pole J, Adams OB. How far to the nearest physician? Rural Small Town Canada Anal Bull. 1999; (5):1-7. Available at: http://www.statcan.gc. ca/pub/21-006-x/21-006-x1998005-eng.pdf. Accessed October 31, 2010.

5. Society of Rural Physicians of Canada. Comparative Regional Statistics; 2010. Available at: http://www. srpc.ca/resources_regional_stats.html. Accessed October 31, 2010.

6. Health Canada. National HIV/AIDS Treatment Information Environmental Scan: Final Report. Ottawa: Health Canada; 2000.

7. Groft JN, Robinson VA. Seeking serenity: living with HIV/AIDS in rural Western Canada. Rural Remote Health. 2007;7(2):1-11.

8. McKinney MM. Variations in rural AIDS epidemiology and service delivery models in the United States. $J$ Rural Health. 2002;18(3):455-466.

9. Ellis DA. The clinical and social aspects of HIV in Australia. Rural HIV: a GP's perspective. Annu Conf Australas HIV Med. 1996;8:59 (abstract no. 46).

10. Shapiro PD. How close is too close?: the negative relationship between knowledge of HIV transmission routes and social distancing tendencies. Soc Sci J. 2005;42(4):629-637.

11. LeBlanc AJ. Examining HIV-related knowledge among adults in the U.S. J Health Soc Behav. 1993;34(1):23-36.

12. Torabi MR, Jeng I. Trends of public knowledge and attitudes related to HIV/AIDS in Indiana. Am J Health Stud. 1999;15(4):203-216.

13. Sutton M, Anthony M-N, Vila C, McLellan-Lemal E, Weidle PJ. HIV testing and HIV/AIDS treatment services in rural counties in 10 southern states: service provider perspectives. J Rural Health. 2010;26(3):240-247.

14. Cates JR, Brewer NT, Fazekas KI, Mitchell CE, Smith JS. Racial differences in HIV knowledge, HPV vaccine acceptability, and related beliefs among rural, southern women. J Rural Health. 2009;25(1):93-97.

15. Fox S, Jones S. The Social Life of Health Information. Washington, DC: Pew Internet and American Life Project; 2009. Available at: http://pewinternet.org/ /media/ 
Files/Reports/2009/PIP_Health_2009.pdf. Accessed October 31, 2010.

16. Williamson K. Discovered by chance: the role of incidental information acquisition in an ecological model of information use. Libr Inf Sci Res. 1998;20(1):23-40.

17. Wathen CN, Harris R. 'I try to take care of it myself.' How rural women search for health information. Qual Health Res. 2007;17(5):639-651.

18. Harris R, Veinot TC, Bella L, Rootman I, Krajnak J. Helpers, gatekeepers and the well-intentioned: the mixed blessing of HIV/AIDS informediation in rural Canada. In: Wathen N, Wyatt S, Harris R, eds. Health Information and Technology: Mediating Health Information in a Changing Socio-Technical Landscape. London: Palgrave; 2008:167-181.

19. Harris R, Veinot TC, Bella, L. A relational perspective on HIV/AIDS information behaviour in rural Canada. Libri. 2010;60(2):129-141.

20. Coleman JS. Social capital in the creation of human capital. AJS. 1988;94(Suppl.):S95-S120.

21. Putnam RD. Bowling Alone: The collapse and revival of American community. New York: Simon and Schuster; 2000.

22. McPherson M, Smith-Lovin L, Cook JM. Birds of a feather: homophily in social networks. Annu Rev Sociol. 2001:27:415-444.

23. Granovetter MS. The strength of weak ties. AJS. 1973;78(6):1360-1380.

24. Rogers EM. Diffusion of innovations. 5th ed. New York: Free Press; 2003.

25. Burt RS. The network structure of social capital. In: Sutton RI, Staw BM, eds. Research in Organizational Behavior: An Annual Series of Analytical Essays and Critical Reviews. Vol 22. New York: Elsevier Science; 2000:345-423.

26. Beggs JJ. Revisiting the rural-urban contrast: personal networks in nonmetropolitan and metropolitan settings. Rural Sociol. 1996;61(2):306-325.

27. Jackson T. Profiles of chronic illness knowledge in a community sample of American adults. J Genet Psychol. 2009;170(3):197-212.

28. du Plessis V, Beshiri R, Bollman R, Clemenson H. Definitions of rural. Rural Small Town Canada Analysis Bull. 2001;3(3):1-17. Available at: http://dsp-psd.pwgsc.gc.ca/ Collection/Statcan/21-006-X/21-006-XIE2001003.pdf. Accessed October 31, 2010.

29. Remis RS, Merid MF. Epidemiology of HIV Infection and AIDS in Elgin-St. Thomas, Huron, Lambton, London, Oxford and Perth Public Health Units, 1981-2003. Toronto, Ontario: Department of Public Health Sciences, University of Toronto; 2006.

30. Veinot TC. Social Capital and HIV/AIDS Information/Help Exchange Networks in Rural Canada [PhD]. London, ON:
Faculty of Information and Media Studies, The University of Western Ontario; 2008.

31. Carey MP, Morrison-Beedy D, Johnson BT. The HIV-knowledge questionnaire: development and evaluation of a reliable, valid, and practical self-administered questionnaire. AIDS Behav. 1997;1(1):61-74.

32. Carey MP, Schroder KEE. Development and psychometric evaluation of the Brief HIV-Knowledge Questionnaire. AIDS Educ Prev. 2002;14(2):174-184.

33. Lalljee M, Palmer-Canton E. Communication and consistency: AIDS talk and AIDS attitudes. J Psychol. 2001;135(1):87-99.

34. Boase J, Wellman B. Measuring Network Size, Tie Strengh and Diversity. Paper presented at: Presentation to the PRI-SSHRC Expert Workshop on Measuring Social Capital for Public Policy; June 8, 2004; Ottawa, Canada.

35. Szreter S, Woolcock M. Health by association? Social capital, social theory, and the political economy of public health. Int J Epidemiol. 2004;33(4):650-667.

36. Herek GM, Capitanio JP, Widaman KF. HIV-related stigma and knowledge in the United States: prevalence and trends, 1991-1999. Am J Public Health. 2002;92(3):371-377.

37. Veinot TC. Interactive acquisition and sharing: understanding the dynamics of HIV/AIDS information networks. J Am Soc Inf Sci Technol. 2009;60(11):2313-2332.

38. Chatman EA. The impoverished life-world of outsiders J Am Soc Inf Sci Technol. 1996;47(3):193-206.

39. Wathen $\mathrm{CN}$, Wyatt S, Harris R (eds). Mediating Health Information: The Go-Betweens in a Changing Socio-Technical Landscape. Basingstoke: Palgrave Macmillan; 2008.

40. Rucinski D. Community boundedness, personal relevance, and the knowledge gap. Communic Res. 2004;31(4):472-495.

41. Veinot TC, Harris RM, Bella L, Rootman I, Krajnak J. HIV/AIDS information exchange in rural communities: preliminary findings from a three province study. Canadian Journal of Information and Library Science. 2006;30(3/4):271-290.

42. Ekos Research Associates Inc. HIV/AIDS Attitudinal Tracking Survey 2006: Final Report. 2006. Available at: http://www.phac-aspc.gc.ca/aids-sida/publication/ por/2006/index-eng.php. Accessed October 31, 2010.

43. Peruga A, Celentano DD. Correlates of AIDS knowledge in samples of the general-population. Soc Sci Med. 1993;36(4):509-524.

44. de Bruyn T. Part of the Solution: A Plan of Action for Canada to Reduce HIVIAIDS-Related Stigma and Discrimination. Montreal, QC: Canadian HIV/AIDS Legal Network; 2005. Available at: http://www.aidslaw.ca/publications/ interfaces/downloadFile.php?ref=39. Accessed October 31,2010 . 